Article

\title{
Bending Resistance and Failure Type Evaluation of Basalt Fiber RPC Beam Affected by Notch and Interfacial Damage Using Acoustic Emission
}

\author{
Hanbing Liu, Xiang Lyu, Yuwei Zhang *, Guobao Luo and Wenjun Li \\ College of Transportation, Jilin University, Changchun 130025, China; lhb@jlu.edu.cn (H.L.); \\ lvxiang18@mails.jlu.edu.cn (X.L.); luogb17@mails.jlu.edu.cn (G.L.); wenjun18@mails.jlu.edu.cn (W.L.) \\ * Correspondence: ywzhang@jlu.edu.cn; Tel.: +86-0431-8509-5446
}

Received: 9 December 2019; Accepted: 3 February 2020; Published: 7 February 2020

\begin{abstract}
Generally, reactive powder concrete (RPC) contains steel fibers often exposed to aggressive environments. Steel fibers in such RPCs are subjected to corrosion in-service, which can significantly change the mechanical properties of the structural components. In this paper, basalt fibers were used to replace steel fibers for preparing a new basalt fiber modified reactive powder concrete (BFRPC). The bending resistance of BFRPC beams was studied, and the crack propagation and failure type of BFRPC beam were monitored by acoustic emission (AE). During the bending test, the failure type of BFRPC was evaluated by AE. Besides, the effects of notch and interfacial damage on the bending resistance and failure type were also studied. During the test, ordinary Reactive Powder Concrete (RPC) without basalt fibers was used as a reference. Results revealed that failure type of the RPC beam and BFRPC beam was mainly caused by shear failure. The notch increased the number of tensile cracks in the beam failure crack, resulting in a decrease in the bending resistance of RPC beam and BFRPC beam. Besides, basalt fiber could improve the toughness and bending resistance of BFRPC beam and increase resistance of the BFRPC beam to notch and interface damage.
\end{abstract}

Keywords: reactive powder concrete; basalt fiber; acoustic emission; notch; interfacial damage

\section{Introduction}

RPC is a new and advanced type of ultra-high-performance concrete that appeared in the 1990s [1]. In RPC material, coarse aggregate is replaced with fine quartz sand compared with ordinary concrete, which makes for RPC with excellent mechanical properties. Besides, RPC is considered to be a new cement-based material with excellent properties that could effectively improve the compactness of concrete material [2,3]. Therefore, RPC material has the characteristics of ultra-high-strength, high toughness, high durability, and high-temperature adaptability, which could effectively increase the spanning capacity. RPC has therefore been widely used in varying infrastructure construction [4].

Similar to ordinary concrete, RPC is prone to brittle failure without fiber $[5,6]$. Therefore, steel fiber (SF) is usually added to RPC to enhance its crack resistance [7]. However, SF is prone to rust, which will deteriorate the durability of the RPC structure in the long-term. Besides, literature has reported that glass fiber (GF) and carbon fiber (CF) can be used in RPC material; GF, however, has poor alkali resistance and $\mathrm{CF}$ is uneconomic $[8,9]$. Basalt Fiber $(\mathrm{BF})$ is a new type of inorganic fiber with natural compatibility and excellent mechanical properties. It is made of pure natural basalt ore and molded by the melt drawing process; there is no wastewater, waste gas, and other industrial waste during its production process. Moreover, the density of BF is similar to that of cement concrete and mortar, so it has a unique advantage for the even distribution of BF in concrete mortar. Previous studies [10-15] have indicated that BF could increase the bending ductility, bending resistance, shear strength, and 
bearing capacity of concrete beams. Garcia et al. [16] and Chandran et al. [17] used BF composite materials to reinforce the wooden and concrete beams, respectively. Krassowska et al. [18] found that $\mathrm{BF}$ had the ability to transmit shear stress in the beam structure. However, there are few studies focused on the application of BF to enhance RPC material properties, and so it is should be paramount to evaluate the application and durability of BF modified RPC materials in road and bridge engineering.

With the development of new technology, many new crack monitoring methods have appeared. Non-extended statistical modeling of electrical emissions were used to predict the fracture of mortar beams by Stergiopoulos et al. [19]. In addition, as a new non-destructive testing method, AE has been widely used for the damage monitoring of various materials [20] such as marble [21], joint specimens [22], buried pipe deformation [23], and polymer structure [24]. Zhou et al. [25] proposed a method to reconstruct the denudation of sedimentary basin by using $\mathrm{AE}$, a technique which is also effective in monitoring the tensile failure mechanism of carbon fiber woven composites [26]. Manterola et al. [27] detected the crack propagation of welded joints based on AE testing and obtained good results. Ylönen et al. [28] evaluated the potential contribution of AE measurements to cavitation damage, concluding that AE signal analysis can be used to monitor the formation of pits without visual examination of the damaged surface. Abouhussien et al. [29] used AE technology to evaluate the compressive strength gain of concrete with different supplementary cementitious materials, finding that the strength gain rate of concrete is directly related to the AE parameters studied. Ali et al. [30] studied the damage evolution of carbon fiber reinforced composites under bending loads, proving the effectiveness of AE in damage determination by scanning electron micrographs. Hakeem et al. [31] used AE signal strength to predict the occurrence of cracks in beams. Calabrese et al. [32] used AE technology to study the cracking characteristics of prestressed concrete beams, clearly identifying the initiation, expansion, and critical failure stages of cracks. Moreover, Shirsendu et al. [33,34] demonstrated the reliability of $\mathrm{AE}$ monitoring for damage sources, proposing a real-time health monitoring framework based on $\mathrm{AE}$, which can effectively identify potential damage initiation/propagation locations in advanced sandwich composite structures. Ohtsu et al. [35] defined new AE parameters, load ratio, and static pressure ratio, to determine structural damage. It can be summarized from previous work that $\mathrm{AE}$ technology is excellent in the fields of crack propagation monitoring, damage monitoring and failure type judgment. Therefore, $\mathrm{AE}$ technique was used in this paper to monitor the crack propagation and failure types of BFRPC beams.

In summary, although there are lots of laboratory studies about the mechanical properties of RPC material, the bending resistance and failure type of BFRPC beams under the effects of the notch and interfacial damage is not clear. In this paper, BF was used to replace SF for modifying RPC materials as BFRPC. The bending resistance of BFRPC beam under the conditions of notch and interfacial damage was analyzed, and the damage type of BFRPC beam was studied by AE. It will lay a foundation for the popularization and application of BFRPC in the actual engineering projects.

\section{AE Technology}

When the material is damaged under external load or internal stress, the strain energy generated by the failure is converted into the elastic wave for release. Bentahar et al. [36] characterized the damage by releasing elastic energy at each step of the material damage process. AE refers to the collection and analysis of such elastic waves by Acoustic devices. Compared to ordinary concrete, the homogeneity of BFRPC is greatly improved, but there are a large number of micro-pores, and many micro-cracks will be generated during the curing process. During the failure process, micro-cracks initiation and propagation of micro-cracks eventually led to the destruction of BFRPC structure. This failure process contains a large number of AE signals. The information contained in the AE signal of the BFRPC beam during this process and the correlation analysis with the mechanical parameters of the RPC beam can be used to understand damage information of the BFRPC beam. 
The information in AE signals is usually expressed by direct and indirect parameters. Direct parameters are the data recorded directly by AE equipment, while indirect parameters are further calculated by direct parameters. Figure 1 shows the basic parameters of AE signal.

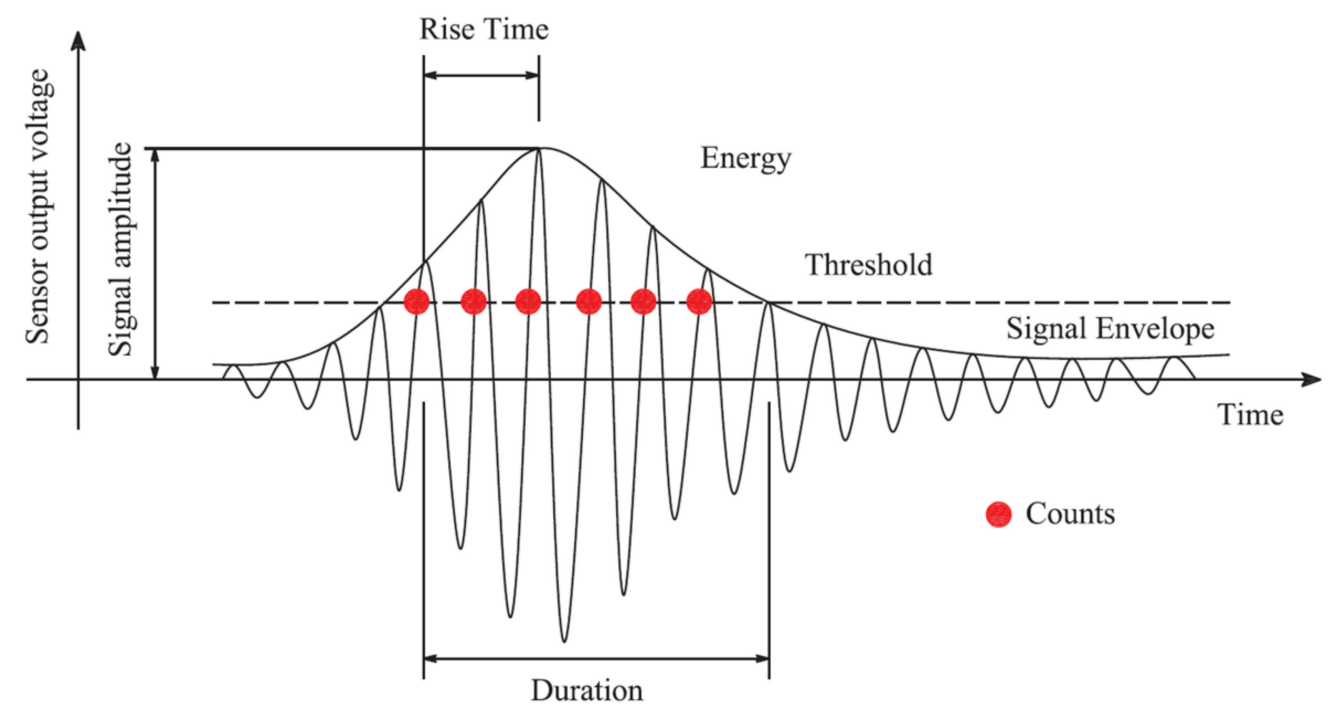

Figure 1. Basic parameters of acoustic emission AE.

As can be seen from Figure 1, the direct parameters include threshold, amplitude, counts, duration, rise time, and energy. The setting of the threshold can effectively filter out the influence of ambient noise on the test data, so as to reflect the real failure condition of the material more truly. Amplitude is the maximum voltage corresponding to the signal peak value. Counts are the number of times that the AE signal exceeds the threshold during the duration. Duration refers to the time interval between the AE signal trigger time and the disappearance time. The rise time refers to the time interval between the AE signal trigger time and peak amplitude time. Energy is the measured area below the AE signal envelope.

Indirect parameters include average frequency $(\mathrm{AF})$ and RA values, etc. In concrete materials, the classification of crack types is proposed, using the combination of the AF values and RA values. This classification technique has been standardized (JCMS 2003) and is shown in Figure 2 [37]. The calculation process is shown in Equations (1) and (2).

$$
\begin{aligned}
\text { AF value } & =\frac{\text { Counts }}{\text { Duration }},(\mathrm{kHz}) \\
\text { RA value } & =\frac{\text { Rise time }}{\text { Amplitude }},(\mathrm{ms} / \mathrm{V})
\end{aligned}
$$

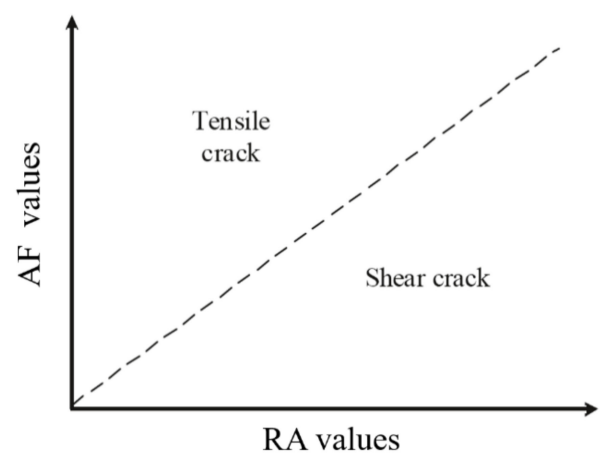

Figure 2. Failures were classified according to average frequency (AF) and RA values. 
When the material deforms locally, tensile waves and shear waves occur at the deformation position. Tensile wave has fast wave velocity, large amplitude, and short rise time, which is characterized as higher AF value and lower RA value in the AE signal. On the contrary, the shear wave velocity is slow. The slower wave velocity leads to longer rise time and duration, which indicates that the AF value is lower, and RA value is higher in the AE signal.

\section{Experimental Details}

\subsection{Materials}

The materials required for BFRPC are quartz sand, quartz powder, silica fume, cement, water, water reducer, and basalt fiber. Quartz sand has the properties that the hardness is 7.0, the silicon content is $99.4 \%$, and the melting point is 1750 degrees. Quartz sand is sieved through $0.3 \mathrm{~mm}$ and $0.6 \mathrm{~mm}$ square holes for further experiments. The chemical composition of quartz sand is shown in Table 1. The size of quartz powder is 400 mesh and the silicon content of quartz powder is more than $98 \%$. The mass fraction of silica fume is $93.3 \%$ and the specific surface area is $18,100 \mathrm{~m}^{2} / \mathrm{kg}$. The P.O 42.5 cement produced by Jilin Yatai Cement Co., Ltd. (Jilin, China) is used. The chemical composition of silica fume and cement is shown in Figure 3. The basic properties of basalt fibers (as shown in Figure 4) are shown in Table 2. In addition, the test steel bar is Q235 hot-rolled round steel bar with a diameter of $8 \mathrm{~mm}$ and a length of $380 \mathrm{~mm}$.

Table 1. Chemical composition of quartz sand (\%).

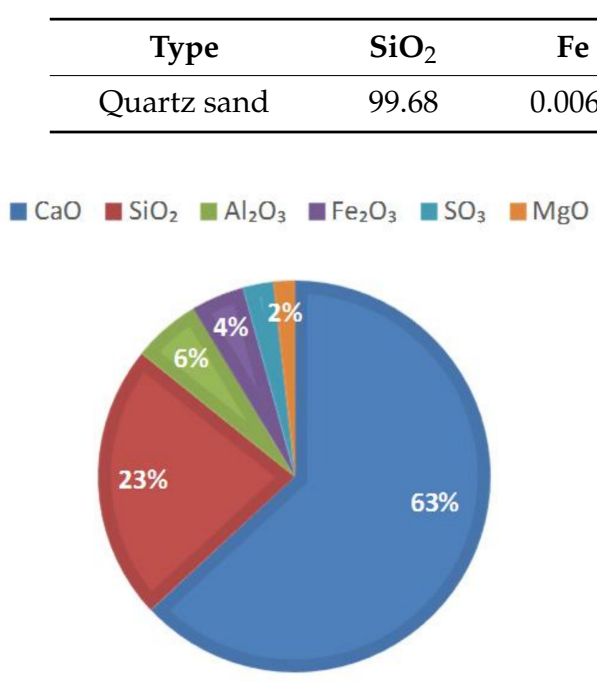

(a)

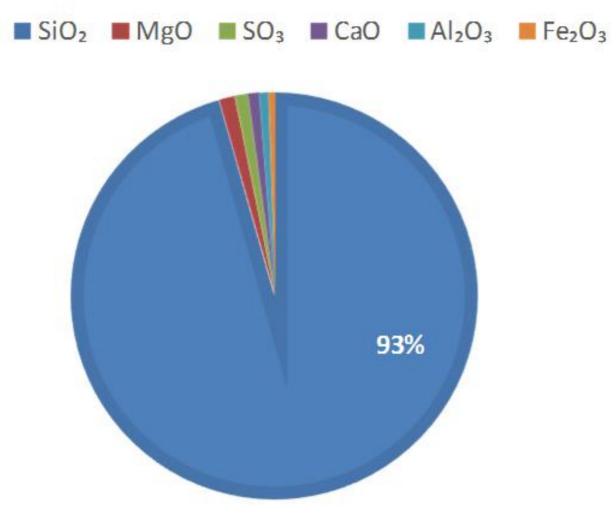

(b)

Figure 3. Chemical composition of cementing materials: (a) Cement; (b) Silica fume.

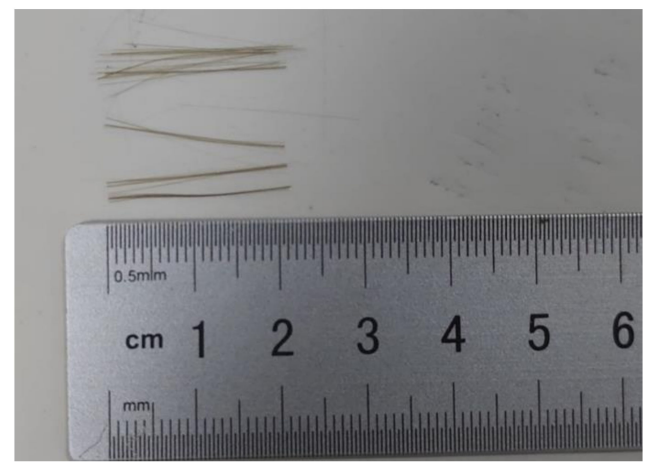

Figure 4. Basalt fiber (BF). 
Table 2. Basic properties of basalt fibers.

\begin{tabular}{cccccccc}
\hline Fiber Type & $\begin{array}{c}\text { Length } \\
(\mathbf{m m})\end{array}$ & $\begin{array}{c}\text { Diameter } \\
(\mu \mathrm{m})\end{array}$ & $\begin{array}{c}\text { Linear } \\
\text { Density } \\
(\text { tex })\end{array}$ & $\begin{array}{c}\text { Tensile } \\
\text { Strength } \\
(\mathbf{M P a})\end{array}$ & $\begin{array}{c}\text { Elastic } \\
\text { Modulus } \\
(\mathrm{GPa})\end{array}$ & $\begin{array}{c}\text { Breaking } \\
\text { Strength } \\
(\mathbf{N} / \text { tex })\end{array}$ & $\begin{array}{c}\text { Elongation } \\
(\%)\end{array}$ \\
\hline Basalt fiber & 22 & 23 & 2392 & 2836 & 62 & 0.69 & 3 \\
\hline
\end{tabular}

The response surface method was adopted to design the mix proportion of this kind of concrete in our previous study [38]. In this study, the best mix proportion obtained by the response surface method was selected. Mix proportions of RPC and BFRPC were shown in Table 3.

Table 3. Mix proportions of RPC and BFRPC $\left(\mathrm{kg} / \mathrm{m}^{3}\right)$.

\begin{tabular}{|c|c|c|c|c|c|c|c|c|}
\hline & \multirow{2}{*}{ Water } & \multirow{2}{*}{ Cement } & \multirow{2}{*}{$\begin{array}{l}\text { Silica } \\
\text { Fume }\end{array}$} & \multicolumn{2}{|c|}{ Quartz Sand } & \multirow{2}{*}{$\begin{array}{l}\text { Quartz } \\
\text { Powder }\end{array}$} & \multirow{2}{*}{$\begin{array}{l}\text { Basalt } \\
\text { Fiber }\end{array}$} & \multirow{2}{*}{$\begin{array}{c}\text { Water } \\
\text { Reducer }\end{array}$} \\
\hline & & & & $0.15 \mathrm{~mm}-0.3 \mathrm{~mm}$ & $0.3 \mathrm{~mm}-0.6 \mathrm{~mm}$ & & & \\
\hline $\mathrm{RPC}$ & 151.5 & 841.8 & 210.4 & 364.2 & 582.8 & 311.4 & 0 & 52.6 \\
\hline
\end{tabular}

\subsection{Sample Preparation}

Three test beams for RPC and BFRPC were made, respectively. Each beam has different conditions, as shown in Table 4. The size of the test beam is designed as $400 \mathrm{~mm} \times 100 \mathrm{~mm} \times 100 \mathrm{~mm}$. In order to enhance the bending resistance of the experimental beam, three steel bars are arranged for each specimen. Figure 5 shows the positions of steel bar, notch, and interfacial damage.

Table 4. Description of test beam conditions.

\begin{tabular}{ccccccc}
\hline Specimen Number & RPC & RPC-N & RPC-N-ID & BFRPC & BFRPC-N & BFRPC-N-ID \\
\hline Notch & $0^{1}$ & $\bullet 2$ & $\bullet$ & 0 & $\bullet$ & $\bullet$ \\
Interfacial Damage & $\bigcirc$ & 0 & $\bullet$ & 0 & 0 & $\bullet$ \\
\hline
\end{tabular}

${ }^{1}$ The item is not included. ${ }^{2}$ The item is included.

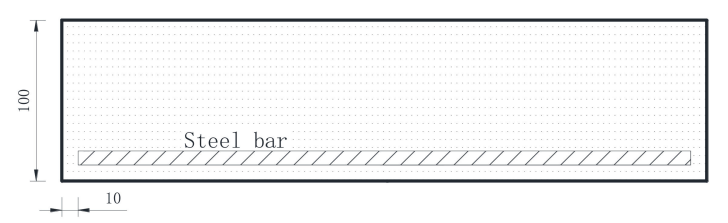

(a)
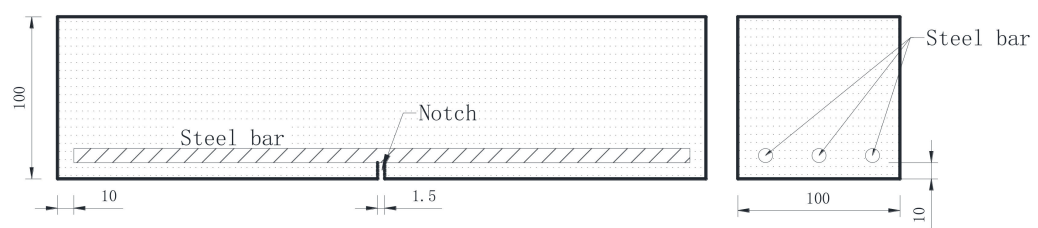

(b)
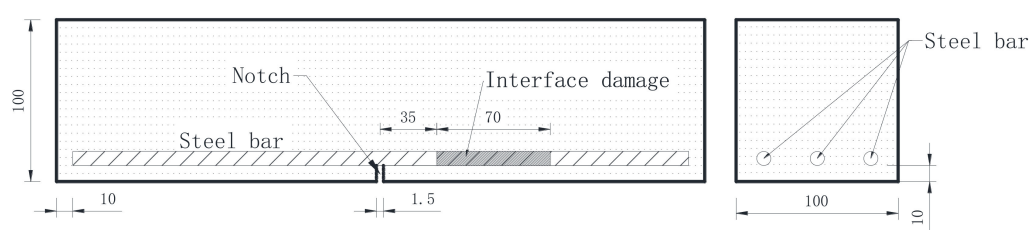

(c)

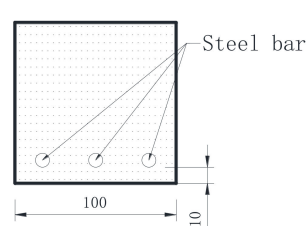

$100 \quad-9$

Figure 5. Front and side view of test beam (cm): (a) RPC and BFRPC; (b) RPC-N and BFRPC-N; (c) RPC-N-ID and BFRPC-N-ID. 
The notch in Figure 5b,c was created by prepositioning, which usually involves inserting a thin copper sheet into the concrete and removing it before curing. However, the notch made by this method is easily filled with surrounding materials in the subsequent curing process, which will affect the accuracy of test results. In this paper, wood sheet is used instead of copper sheet. After the specimen is cured and molded, the wood sheet is taken out, which can avoid the test error caused by the preset copper sheet. Besides, the interfacial damage in Figure $5 \mathrm{c}$ is achieved by wrapping filter paper on the surface of steel bars.

\subsection{Experimental Procedure}

The specimen should be cured in steam at $90{ }^{\circ} \mathrm{C}$ for $48 \mathrm{~h}$. Then hydraulic testing machine was used to test the bending resistance of each test beam. At the same time, AE technology was used to monitor the crack propagation and failure mode of the test beam. The experimental procedure is shown in Figure 6.

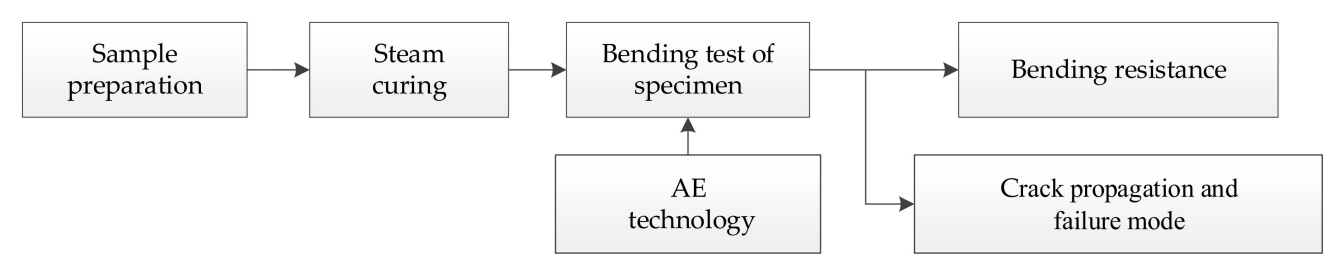

Figure 6. Experimental procedure.

\subsection{Bending Test}

The three-point bending is adopted to conduct the bending test for RPC and BFRPC beams. WAW-300kN microcomputer controlled electro-hydraulic servo universal testing machine was selected as the loading device. The calculated span of the test beam was $300 \mathrm{~mm}$. Loading layout and AE sensors layout are shown in Figure 7.

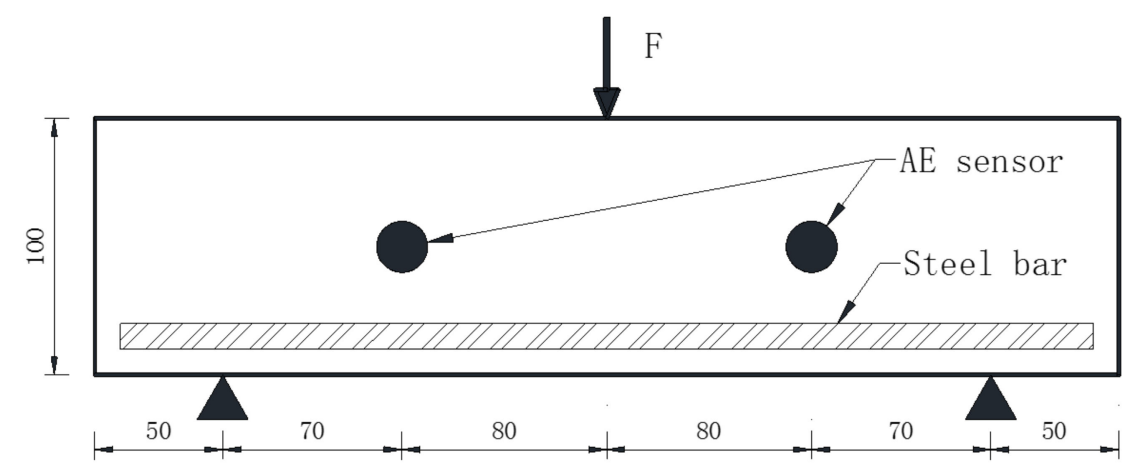

Figure 7. Loading and AE sensors layout (mm).

AE equipment SAEU2S was used to monitor crack propagation of RPC and BFRPC beams under bending loads. The $\mathrm{AE}$ data acquisition system was used to collect $\mathrm{AE}$ parameters and $\mathrm{AE}$ wave data during the bending test. First, AE sensor with a frequency range of $60-400 \mathrm{kHz}$ and model SR150M were fixed on one side of the beam to monitor the crack propagation. Then, signal connection judgment should be made before test to ensure that AE sensor was well fixed. The next step is to set the $\mathrm{AE}$ acquisition parameters. The threshold of $\mathrm{AE}$ acquisition system was set as $40 \mathrm{~dB}$ to filter environmental noise. Low-pass and high-pass filters were set to $20 \mathrm{kHz}$ and $400 \mathrm{kHz}$, respectively, to filter out electrical noise. The sampling frequency was 5MSPS.The peak definition time, hit definition time and hit lockout time were set to 50, 150 and $300 \mathrm{~ms}$, respectively, to ensure correct identification of the signal. Figure 8 shows the experimental setups for the bending test and $\mathrm{AE}$ test. 


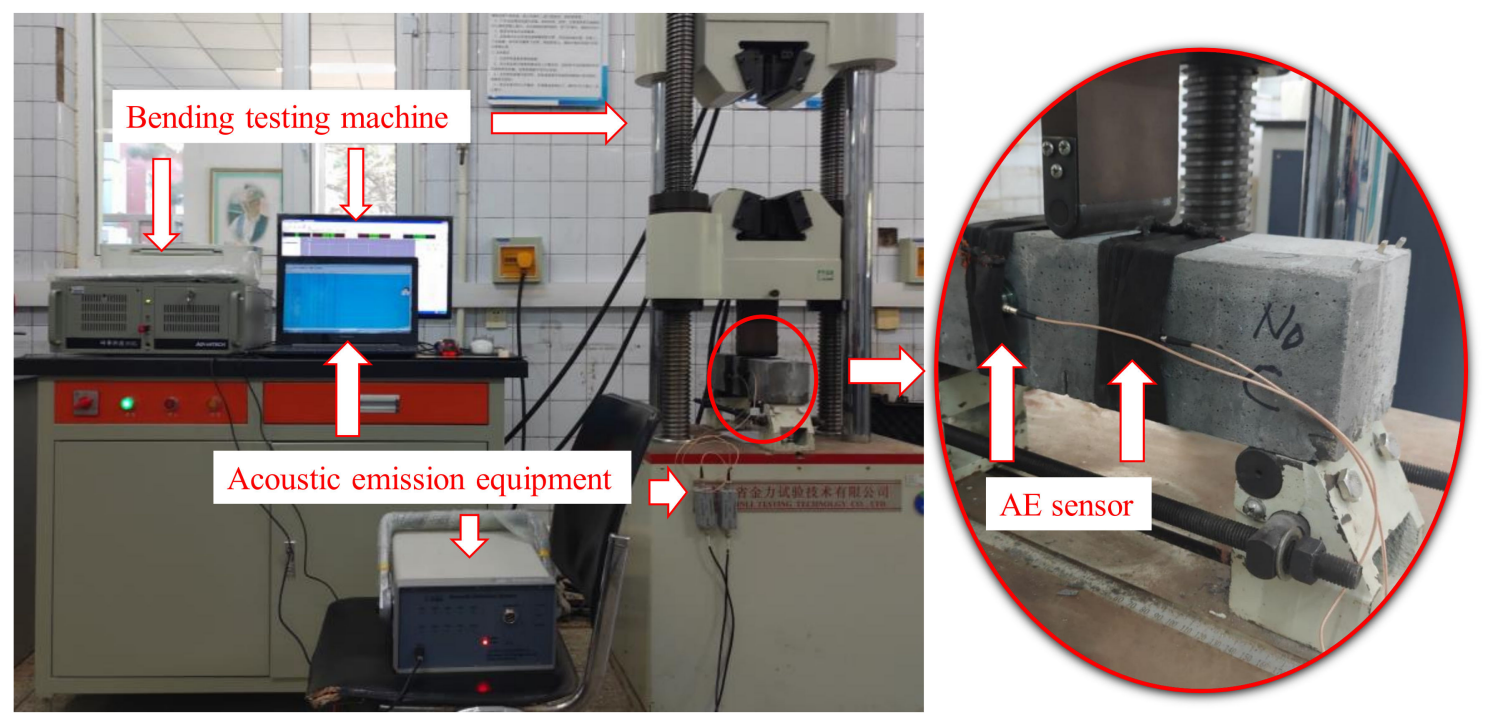

Figure 8. Experimental setups for the bending test and AE test.

\section{Results and Discussion}

\subsection{Bending Resistance}

The failure load of all beams is shown in Figure 9.

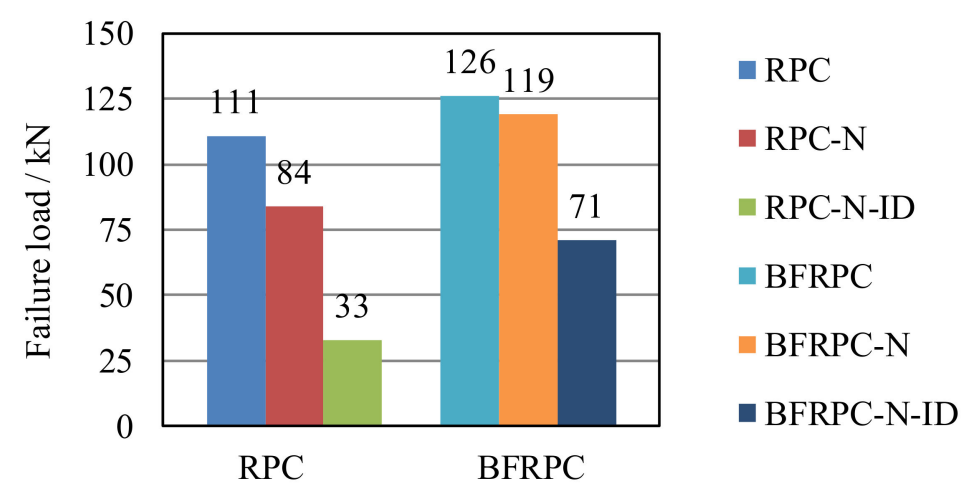

Figure 9. Maximum bearing capacity.

As can be seen from Figure 9, due to existence of the notch, failure loads of the RPC beam and BFRPC beam are reduced by $27 \mathrm{kN}$ and $7 \mathrm{kN}$, respectively. Under the influence of interfacial damage, the failure load of RPC beam and BFRPC beam are reduced by $51 \mathrm{kN}$ and $48 \mathrm{kN}$, respectively. The results show that both notch and interfacial damage can reduce the bending resistance of RPC and BFRPC beam, and the interfacial damage has a greater impact on the bending resistance. The reason for this is that the notch accelerates the formation and expansion of the cracks and reduces the bending capacity of the beam. However, the interfacial damage directly causes the insufficient bonding force between the steel bar and the concrete, which reduces the local mechanical properties of the beam body in the damaged area. It is a macroscopic manifestation of the influence of large-area corrosion of the steel bar on the stress characteristics of the beam. Besides, the failure load of the BFRPC beam was greater than that of the RPC beam under the corresponding conditions, which indicates that BF can increase the failure load of RPC and reduce the adverse effects of the notch and interfacial damage on the failure load. 


\subsection{AE Basic Parameter}

The changes in AE parameters can reflect the information about the concrete failure process. In order to select appropriate $\mathrm{AE}$ parameters to understand the influence of $\mathrm{BF}$, notch and interfacial damage on the bending performance of RPC beam, the BFRPC beam was taken as an example, and the variation diagram of its load curve and $\mathrm{AE}$ basic parameters (cumulative energy, hits, cumulative counts, amplitude, and duration) with the loading time are drawn in Figure 10.

As shown in Figure 10, at the time of $700 \mathrm{~s}$, there is an obvious abrupt change in the load curve, which is caused by the tensile failure of the concrete at the bottom of the beam. At this point, the duration of AE parameter (shown in Figure 10e) suddenly increased. At $2500 \mathrm{~s}$, the beam is damaged and the duration increased rapidly again, which indicates that duration of the AE parameter is consistent with the change of beam structure. Therefore, the loading process of the beam can be divided into three stages by the sudden increase of the duration.

In the first stage, $0-700 \mathrm{~s}$, the cumulative energy, hits, and cumulative counts of AE parameters are too small, so it can be ignored, and the amplitude is within the range of $40-60 \mathrm{~dB}$. This phenomenon indicates that the BFRPC beam is in the early stage of loading, with fewer micro-cracks and a smaller number and strength of AE events. This stage belongs to the cracks initiation stage. Besides, in the second stage, 700-2500 s, the cumulative energy, hits and cumulative counts of AE parameters begin to increase and increasing rates of all these parameters are relatively stable. The amplitude also increases, and the range of this parameter is $40-80 \mathrm{~dB}$. This phenomenon indicates that the cracks in BFRPC beam begin to expand, and this stage belongs to the unstable development stage of cracks. In addition, in the third stage, after $2500 \mathrm{~s}$, cumulative energy, hits, and cumulative counts of AE parameters increase sharply. This indicates that the cracks expand rapidly, which leads to the failure of the beam. This stage belongs to the failure stage.

The above three stages show that $\mathrm{AE}$ parameters could accurately reflect the damage degree of the RPC beam structure from the scale of micro-cracks and effectively judge the failure stage of the beam body. Next, the cumulative energy and amplitude parameters are selected to further study the influence of BF, notch, and interfacial damage on the bending performance of RPC beams. The AE cumulative energy and amplitude of RPC beam, BFRPC beam, BFRPC-N beam, and BFRPC-N-ID beam are selected for analysis. The cumulative energy and amplitude change curves with time are shown in Figures 11 and 12, respectively.

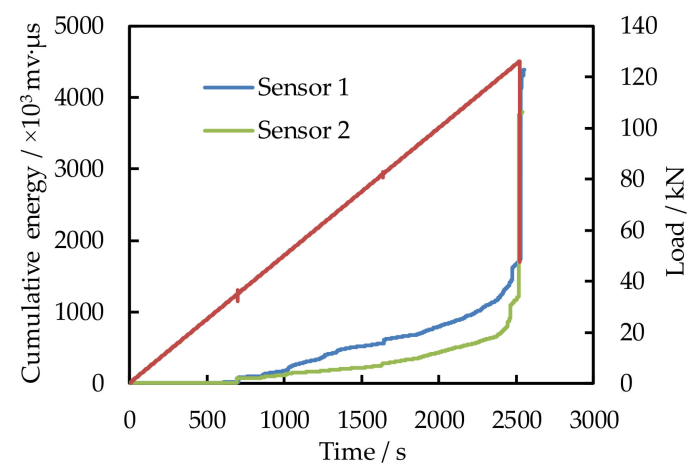

(a)

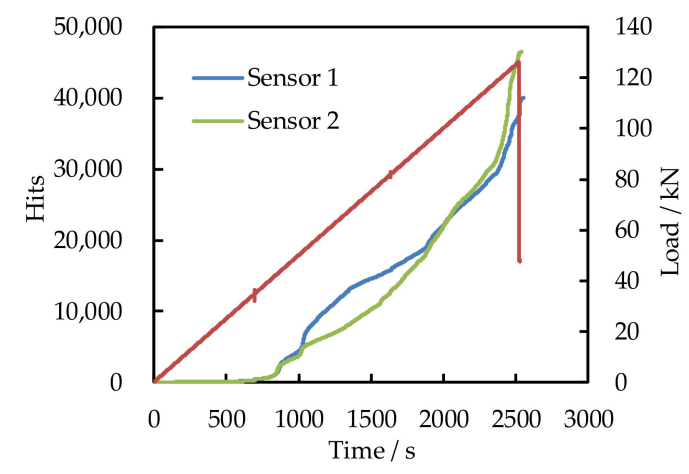

(b)

Figure 10. Cont. 


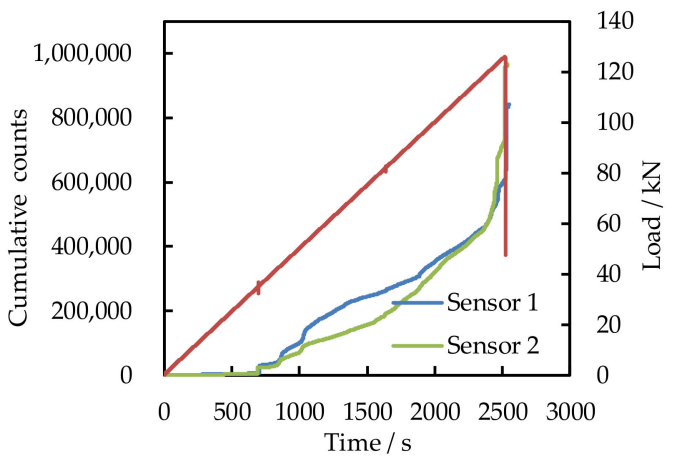

(c)

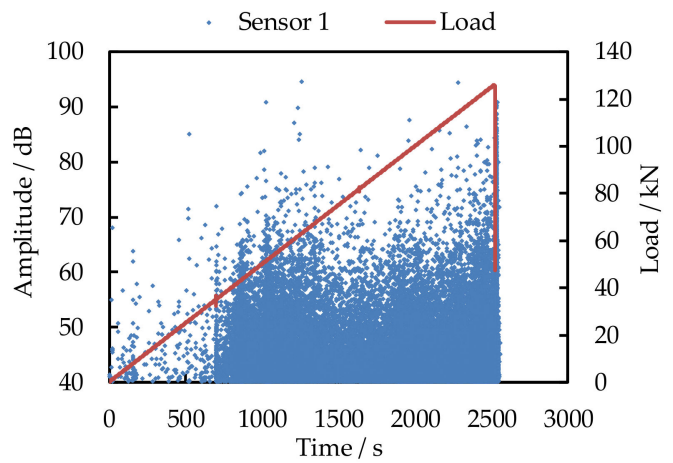

(d)

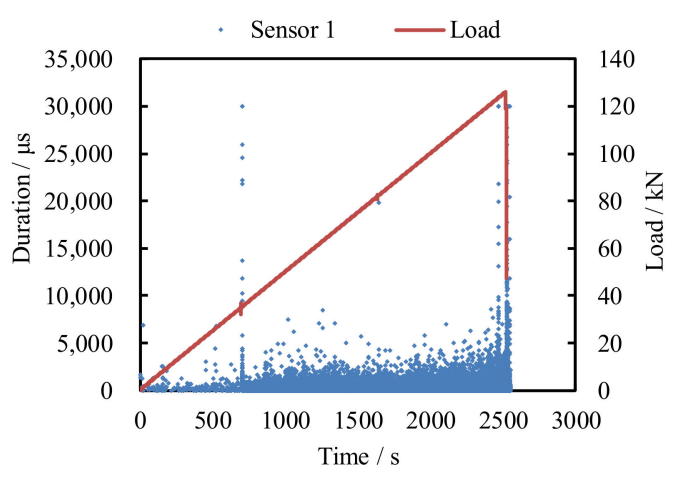

(e)

Figure 10. Basic AE parameters of BFRPC beam: (a) Cumulative energy; (b) Hits; (c) Cumulative counts; (d) Amplitude; (e) Duration.

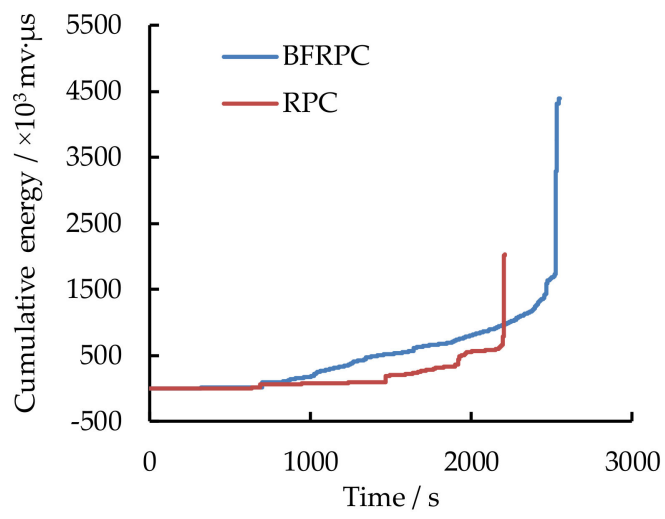

(a)

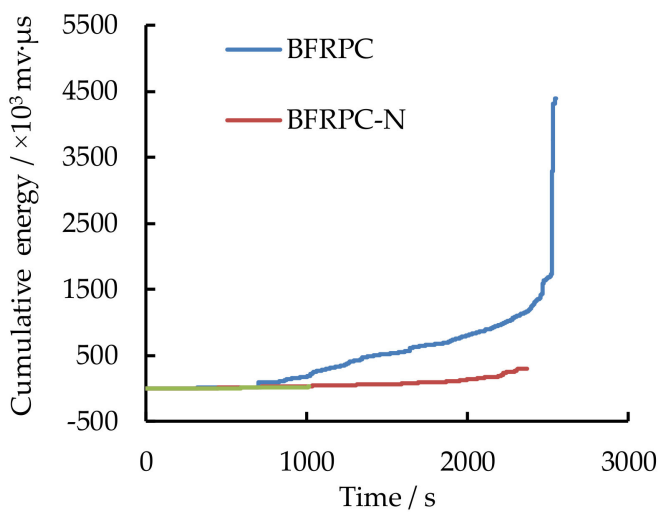

(b)

Figure 11. Influence of different factors on $\mathrm{AE}$ cumulative energy: (a) BF; (b) notch and interfacial damage. 


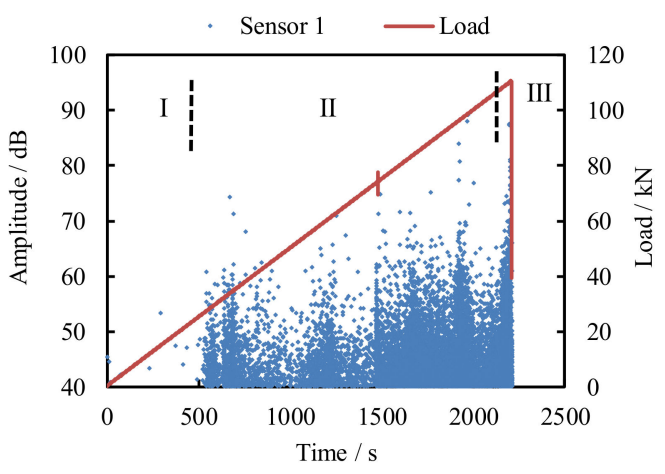

(a)

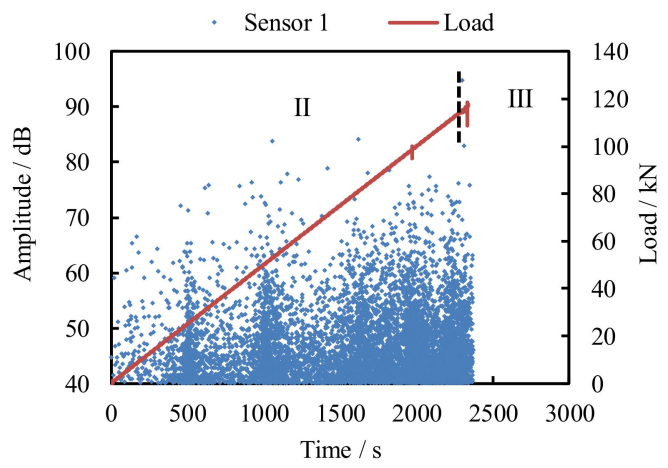

(c)

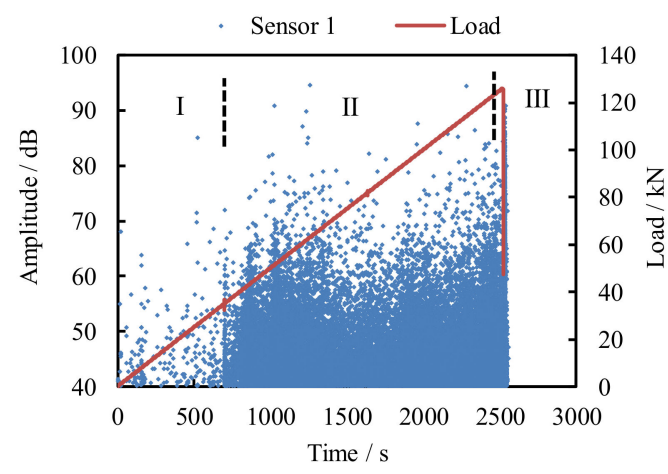

(b)

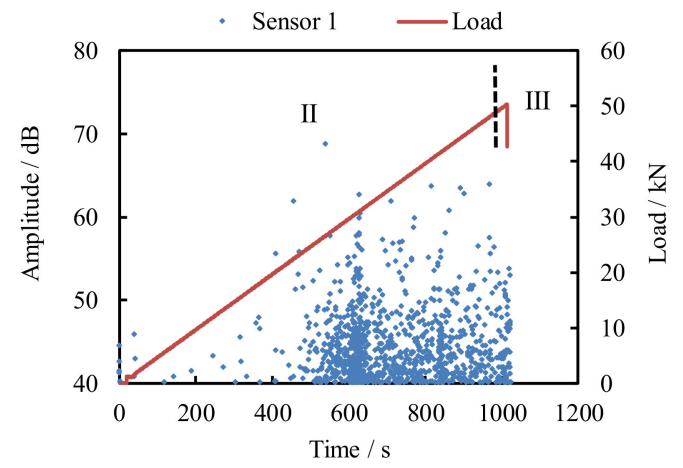

(d)

Figure 12. AE parameters amplitude: (a) RPC beam; (b) BFRPC beam; (c) BFRPC-N beam; (d) BFRPC-N-ID beam.

As can be seen from Figure 11, after $700 \mathrm{~s}$, the cumulative energy begins to increase. At that time, the beam stress enters the second stage and the cracks begin to expand, which is suitable for analyzing the influence of $\mathrm{BF}$, notch, and interfacial damage on the bending performance of the beam. Figures 11a and $12 \mathrm{a}, \mathrm{b}$ can reflect that the cumulative energy and amplitude of the BFRPC beam are greater than that of the RPC beam in the second stage. The reason is that BFPRC belongs to BF reinforced material. In the process of material cracking, both $\mathrm{BF}$ and concrete will be pulled to break. Compared to RPC, the $\mathrm{AE}$ signals in BFRPC not only generated from the broken concrete but also from the broken BF. In the third stage, the cumulative energy of the BFRPC beam is greater than that of the RPC beam, because the accumulated deformation energy of $\mathrm{BF}$ reaches the limited value that it can bear. $\mathrm{BF}$ is pulled out or fractures, and the potential energy absorbed through BF deformation is released instantly, generating more AE signals and causing a sharp increase in cumulative energy. In addition, Figure 11a shows that in the $1500 \mathrm{~s}$ and $2000 \mathrm{~s}$, the accumulated energy of RPC beam has a mutation but BFRPC beam has no mutation, which indicates that RPC beam is prone to brittle fracture. BF can absorb part of the external load potential energy through deformation, reducing the potential energy used for the crack expansion. Furthermore, the cracks propagation is controlled and the toughness of RPC is improved.

Figures $11 \mathrm{~b}$ and $12 \mathrm{~b}, \mathrm{c}$ show that the $\mathrm{AE}$ event number, cumulative energy, and amplitude of BFRPC-N beam are significantly lower than that of BFRPC beam, and the AE event number, cumulative energy, and amplitude of BFRPC-N-ID beam are significantly lower than that of BFRPC-N beam. Moreover, it cannot be obviously observed that the energy release when the damage of BFRPC-N beam and BFRPC-N-ID beam occurs. The reason is that the external load potential energy will not be transferred to $\mathrm{BF}$, and the damage will be released directly at the place notch and interfacial damage, which is also the essential reason why the notch and interfacial damage reduces the bending resistance of the beam. Therefore, notch and interfacial damage should be monitored in the actual engineering projects. 


\subsection{Failure Type}

According to Figure 6, AE parameters AF and RA can be used to classify the failure modes of cracks formed in test beams. When the RA value is large and the AF value is small, the failure cracks mainly belong to shear cracks, which are generated by shear waves. On the contrary, when AF value is large and RA value is small, the cracks mainly belong to tensile cracks that are generated by tensile waves. Figure 13 shows the curves of RA and AF values of BFRPC beam and BFRPC-N beam with experimental duration.

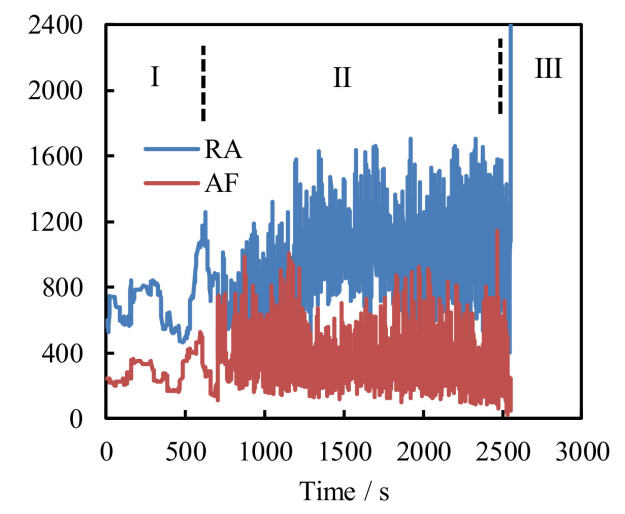

(a)

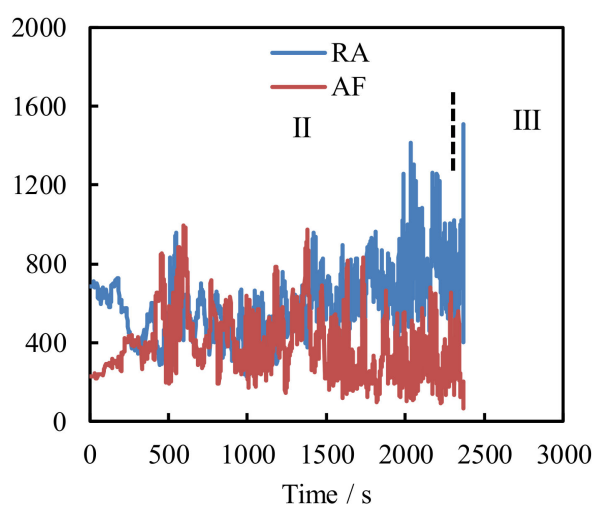

(b)

Figure 13. AE parameters RA and AF: (a) BFRPC beam; (b) BFRPC-N beam.

It can be seen from Figure 13 that the variation tendency of the RA values and AF values of the AE signals generated from BFRPC beam and BFRPC-N beam are almost the same, indicating that the cracks formed in both the test beams are composed of shear cracks and tensile cracks. Furthermore, in order to distinguish that the failure cracks formed in test beams belong to tensile or shear cracks more clearly, parameters $\Phi$ is defined and calculated by Equation (3).

$$
\Phi=\left\{\begin{array}{c}
\mathrm{RA}-\mathrm{AF}>0, \text { Shear cracks predominate } \\
\mathrm{RA}-\mathrm{AF}<0, \text { Tensile cracks predominate }
\end{array}\right.
$$

$\Phi>0$ indicates that the cracks that formed in the beams mostly belong to shear mode cracks. The larger the $\Phi$ value is, the greater the damage caused by shear action. On the contrary, if $\Phi<$ 0 , cracks that formed in the beams belong to tensile mode cracks. The smaller the $\Phi$ value is, the greater the damage caused by tensile action. In addition, the mutation of the $\Phi$ value curve shows that failure mode changes within the beam. In order to analyze the proportion of these two kinds of crack modes more clearly, the percentage of the AE signals with the characteristics of $\Phi>0$ or $\Phi<0$ is also calculated in this paper. In addition, RPC beam, BFRPC beam, BFRPC-N beam and BFRPC-N-ID beam are selected to understand the influence of $\mathrm{BF}$, notch, and interfacial damage on the beam failure cracks. $\Phi$ value curves are shown in Figure 14, and all the curves can be divided into three stages by the same method discussed in Section 4.2. Figure 14c,d have no crack initiation stage due to the existence of notch, which is met well with the phenomenon in the bending test procedure. 


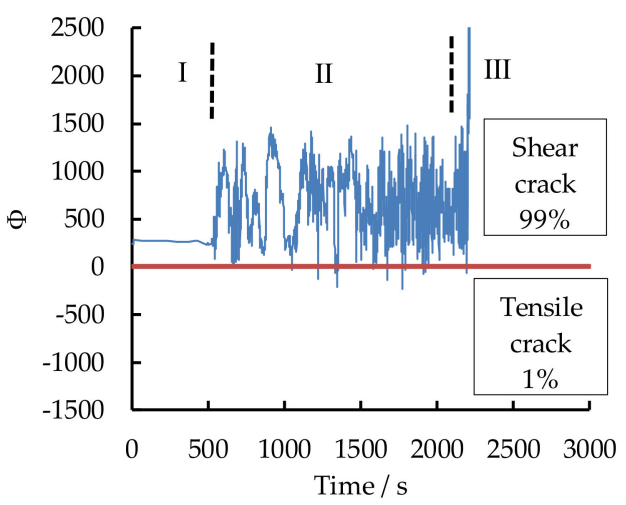

(a)

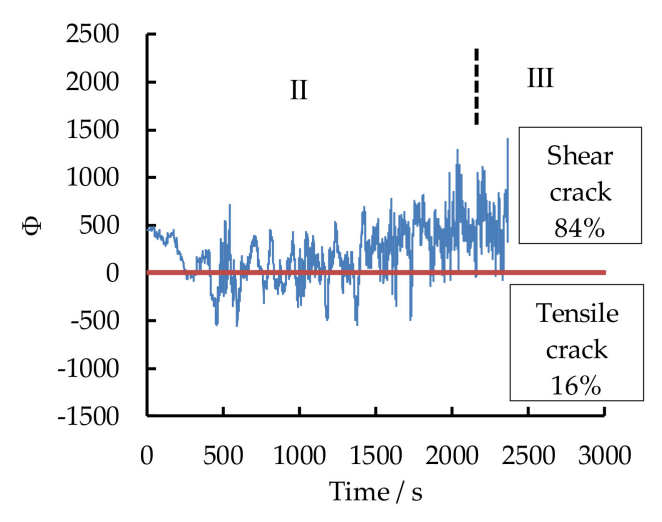

(c)

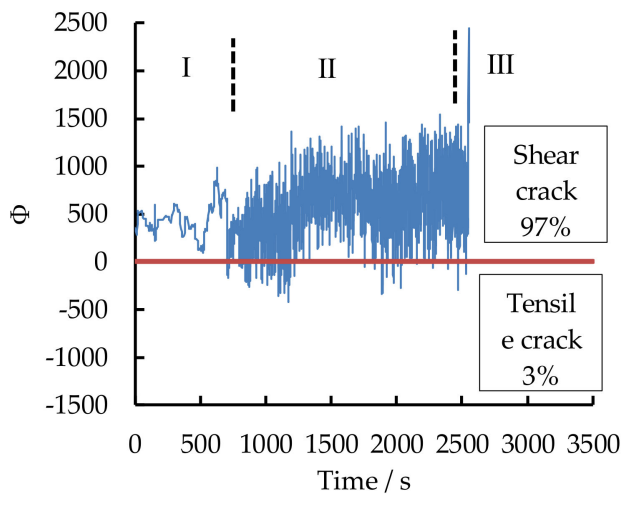

(b)

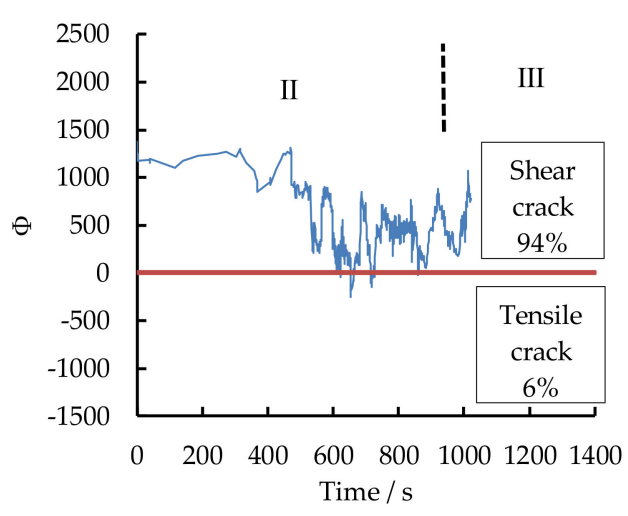

(d)

Figure 14. RA-AF association analysis: (a) RPC beam; (b) BFRPC beam; (c) BFRPC-N beam; (d) BFRPC-N-ID beam.

It can be seen from Figure 14 that shear cracks of all RPC beams account for more than $80 \%$ of the total cracks, indicating that shear mode plays the dominant role in the beam failure process, which can infer that flexure strength of both RPC and BFRPC beam is such big that the possibility of tensile failure occurs is tiny during their service life in the actual engineering projects.

Besides, as seen from Figure 14a,b, when the beam contains BF material, $\Phi$ value of beam in the second stage has an obvious increasing tendency. The reason is that the bridging action from $\mathrm{BF}$ could transform the tensile mode cracks to shear mode cracks. Compared to the BFRPC beam in Figure $14 \mathrm{~b}, \mathrm{c}$, the proportion of shear cracks in BFRPC-N beam reduces by $13 \%$ and the tensile cracks increases by $13 \%$, indicating that notch causes more tensile failure of concrete, which is due to the stress concentration caused by the notch, which accelerates the rapid destruction of the material. This is also the main reason for the reduction of bending resistance caused by the notch. The notch is in the middle of the bottom of the beam. When the beam is subjected to bending load, the material at the notch of the beam will be subjected to more tensile action, which will lead to more tensile cracks.

Moreover, as can be seen from Figure 14c, d, compared with BFRPC-N beam, the proportion of tensile mode cracks formed in the BFRPC-N-ID beam are reduced by $10 \%$, and $\Phi$ value decreases along with the experimental duration. It shows that the combined action of interfacial damage and notch further reduces the contribution of concrete materials properties to the bending resistance of the test beams. The interfacial damage reduces the area of the contact surface between the steel bar and the concrete. Once the steel bar is stressed, the effective bond force decreases, and the concrete on the contact surface is instantly damaged by the steel bar, resulting in the number of shear mode cracks 
increase around the steel bar, which could also explain why the bending resistance of RPC-N-ID beam is the smallest.

\section{Conclusions}

In this paper, BF was used to replace SF for modifying RPC materials as BFRPC. Besides, notch and interfacial damage was treated as the typical deteriorated factor of durability and applied for breaking the prepared RPC and BFRPC test beams for analyzing the influence of notch and interfacial damage on the bending resistance of both the two kinds of test beams. Besides, AE technology was employed for analyzing the failure type and crack modes in a microscopic cracking level. The following conclusions can be achieved:

(1) Failure of the RPC beam and BFRPC beam is mainly caused by shear action.

(2) The AE signals show that the stress concentration caused by the notch will increase the number of tensile cracks in the beams, and the interfacial damage reduces the resistance to shear action.

(3) BF is an excellent material to modify RPC material. BF can not only improve the toughness and bending resistance of BFRPC beam, but also increase the resistance of BFRPC beam to the notch and interface damage.

Engineers and technicians can utilize AE basic parameters and RA-AF value curves to evaluate the damage and cracking status of in-service RPC or modified RPC structures effectively.

Author Contributions: H.L. conceived of and designed the experiments. X.L. analyzed the data and wrote the paper. Y.Z. investigated the experiments. G.L. audited the content. W.L. reviewed the content. All authors have read and agreed to the published version of the manuscript.

Funding: This research was funded by the Industrial Technology Research \& Development Special Project of Jilin Province (2018C042-1) and the Transportation Science and Technology Program of Jilin Province (2018-1-9).

Acknowledgments: The authors would like to express their appreciation for the anonymous reviewers for their constructive suggestions and comments to improve the quality of the paper.

Conflicts of Interest: The authors declare no conflict of interest.

\section{References}

1. Richard, P.; Cheyrezy, M. Composition of reactive powder concretes. Cem. Concr. Res. 1995, 25, 1501-1511. [CrossRef]

2. Graybeal, B.A. Material property characterization of ultra-high performance; No. FHWA-HRT-06-103; Federal Highway Administration: McLean, VA, USA, 2006.

3. Richard, P.; Cheyrezy, M.H. Reactive powder concretes with high ductility and 200-800mpa compressive strength. ACI Spec. Publ. 1994, 144, 507-518.

4. Wille, K.; Naaman, A.E.; Parra-Montesinos, G.J. Ultra-high performance concrete with compressive strength exceeding $150 \mathrm{MPa}$ (22 ksi): A simpler way. ACI Mater. J. 2011, 108, 46-54.

5. Aitcin, P.C. Cements of yesterday and today-Concrete of tomorrow. Cem. Concr. Res. 2000, 30, 1349-1359. [CrossRef]

6. Ple, O.; Bayard, O. Preliminary study of multiscale analysis in fibre reinforced concrete. Mater. Struct. 2002, 35, 279-284. [CrossRef]

7. Tang, K.K. Stray alternating current (AC) induced corrosion of steel fibre reinforced concrete. Corros. Sci. 2019, 152, 153-171. [CrossRef]

8. Dadej, K.; Bienias, J.; Surowska, B. On the effect of glass and carbon fiber hybridization in fiber metal laminates: Analytical, numerical and experimental investigation. Compos. Struct. 2019, 220, 250-260. [CrossRef]

9. Reihanian, M.; Dashtbozorg, M.; Baghal, S.M.L. Fabrication of glass/carbon fiber-reinforced Al-based composites through deformation bonding. J. Compos. Mater. 2019, 53, 2531-2543. [CrossRef]

10. Dias, D.P.; Thaumaturgo, C. Fracture toughness of geopolymeric concretes reinforced with basalt fibers. Cem. Concr. Compos. 2005, 27, 49-54. [CrossRef] 
11. Elgabbas, F.; Vincent, P.; Ahmed, E.A.; Benmokrane, B. Experimental testing of basalt-fiber-reinforced polymer bars in concrete beams. Compos. Part B Eng. 2016, 91, 205-218. [CrossRef]

12. Abed, F.; Alhafiz, A.R. Effect of basalt fibers on the flexural behavior of concrete beams reinforced with BFRP bars. Compos. Struct. 2019, 215, 23-34. [CrossRef]

13. Seis, M.; Beycioglu, A. Bond performance of basalt fiber-reinforced polymer bars in conventional Portland cement concrete: A relative comparison with steel rebar using the hinged beam approach. Sci. Eng. Compos. Mater. 2017, 24, 909-918. [CrossRef]

14. Alnahhal, W.; Aljidda, O. Flexural behavior of basalt fiber reinforced concrete beams with recycled concrete coarse aggregates. Constr. Build. Mater. 2018, 169, 165-178. [CrossRef]

15. Sarmah, M.; Roy, B.; Mozumder, R.A.; Laskar, A.I. Effect of chopped basalt fibers on the cyclic behavior of RCC beam-column subassemblies. Arab. J. Sci. Eng. 2018, 43, 1865-1874. [CrossRef]

16. Garcia, P.D.; Escamilla, A.C.; Garcia, M.N.G. Bending reinforcement of timber beams with composite carbon fiber and basalt fiber materials. Compos. Part B Eng. 2013, 55, 528-536. [CrossRef]

17. Chandran, A.; Neelamegam, M. Flexural behaviour of strengthened RC beams with multi-directional basalt fibre-reinforced polymer composites. Arch. Civ. Eng. 2015, 61, 45-58. [CrossRef]

18. Krassowska, J.; Kosior-Kazberuk, M. Failure mode of basalt fibre reinforced concrete beams. In Proceedings of the 3rd World Multidisciplinary Civil Engineering, Architecture, Urban Planning Symposium, Prague, Czech Republic, 17-21 June 2019; p. 471.

19. Stergiopoulos, C.; Stavrakas, I.; Triantis, D.; Vallianatos, F.; Stonham, J. Predicting fracture of mortar beams under three-point bending using non-extensive statistical modeling of electric emissions. Phys. A 2015, 419, 603-611. [CrossRef]

20. Zelenyak, A.; Hamstad, M.A.; Sause, M.G.R. Modeling of acoustic emission signal propagation in waveguides. Sensors 2015, 15, 11805-11822. [CrossRef]

21. Lotidis, M.A.; Nomikos, P.P.; Sofianos, A.I. Laboratory Study of the Fracturing Process in Marble and Plaster Hollow Plates Subjected to Uniaxial Compression by Combined Acoustic Emission and Digital Image Correlation Techniques. Rock Mech. Rock Eng. 2019, 1-9. [CrossRef]

22. Naderloo, M.; Moosavi, M.; Ahmadi, M. Using acoustic emission technique to monitor damage progress around joints in brittle materials. Theor. Appl. Fract. Mech. 2019, 104, 102368. [CrossRef]

23. Smith, A.; Moore, I.D.; Dixon, N. Acoustic Emission Sensing of Pipe-Soil Interaction: Full-Scale Pipelines Subjected to Differential Ground Movements. J. Geotech. Geoenviron. 2019, 145, 04019113. [CrossRef]

24. Lainé, E.; Grandidier, J.-C.; Cruz, M.; Gorge, A.-L.; Bouvy, C.; Vaes, G. Acoustic emission description from a damage and failure scenario of rotomoulded polyolefin sandwich structure subjected to internal pressure for storage applications. Mech. Ind. 2020, 21, 105. [CrossRef]

25. Zhou, W.; Zhang, P.-F.; Zhang, Y.-N. Acoustic Emission Based on Cluster and Sentry Function to Monitor Tensile Progressive Damage of Carbon Fiber Woven Composites. Appl. Sci. 2018, 8, 2265. [CrossRef]

26. Wei, S.; Shang, Y.; Li, Y. Application of Acoustic Emission to Estimation of Strata Denudation: A Case Study from the Ordos Basin, China. Sustainability 2019, 11, 861. [CrossRef]

27. Manterola, J.; Aguirre, M.; Zurbitu, J.; Renart, J.; Turon, A.; Urresti, I. Using acoustic emissions (AE) to monitor mode I crack growth in bonded joints. Eng. Fract. Mech. 2020, 224, 106778. [CrossRef]

28. Ylönen, M.; Saarenrinne, P.; Miettinen, J.; Franc, J.-P.; Fivel, M.; Laakso, J. Estimation of Cavitation Pit Distributions by Acoustic Emission. J. Hydraul. Eng. 2020, 146, 04019064. [CrossRef]

29. Abouhussien, A.A.; Hassan, A.A.A. Monitoring early age strength gain of SCC with different supplementary cementitious materials using acoustic emission sensors. Constr. Build. Mater. 2019, 229, 116858. [CrossRef]

30. Ali, H.Q.; Emami Tabrizi, I.; Khan, R.M.A.; Tufani, A.; Yildiz, M. Microscopic analysis of failure in woven carbon fabric laminates coupled with digital image correlation and acoustic emission. Compos. Struct. 2019, 230, 111515. [CrossRef]

31. Hakeem, Z.A.; Noorsuhada, M.N.; Azmi, I.; Syafeekha, M.S.N.; Noor, M.S.S. Analysis of acoustic emission cumulative signal strength of steel fibre reinforced concrete (SFRC) beams strengthened with carbon fibre reinforced polymer (CFRP). AIP Conf. Proc. 2017, 1901, 050007.

32. Calabrese, L.; Campanella, G.; Proverbio, E. Identification of corrosion mechanisms by univariate and multivariate statistical analysis during long term acoustic emission monitoring on a pre-stressed concrete beam. Corros. Sci. 2013, 73, 161-171. [CrossRef] 
33. Sikdar, S.; Mirgal, P.; Banerjee, S.; Ostachowicz, W. Damage-induced acoustic emission source monitoring in a honeycomb sandwich composite structure. Compos. Part B Eng. 2019, 158, 179-188. [CrossRef]

34. Sikdar, S.; Ostachowicz, W.; Pal, J. Damage-induced acoustic emission source identification in an advanced sandwich composite structure. Compos. Struct. 2018, 202, 860-866. [CrossRef]

35. Ohtsu, M.; Uchida, M.; Okamoto, T.; Yuyama, S. Damage assessment of reinforced concrete beams qualified by acoustic emission. Struct. J. 2002, 99, 411-417.

36. Bentahar, M.; Guerjouma, R.E. Monitoring progressive damage in polymer-based composite using nonlinear dynamics and acoustic emission. J. Acoust. Soc. Am. 2009, 125, El39-El44. [CrossRef]

37. JCMS-III B5706. Monitoring Method for Active Cracks in Concrete by Acoustic Emission; Federation of Construction Materials Industries: Tokyo, Japan, 2003.

38. Liu, H.; Liu, S.; Wang, S.; Gao, X.; Gong, Y. Effect of mix proportion parameters on behaviors of basalt fiber RPC based on box-behnken model. Appl. Sci. 2019, 9, 2031. [CrossRef]

(C) 2020 by the authors. Licensee MDPI, Basel, Switzerland. This article is an open access article distributed under the terms and conditions of the Creative Commons Attribution (CC BY) license (http://creativecommons.org/licenses/by/4.0/). 